\title{
CORONAVIRUS
}

\section{Single-cell RNA sequencing reveals SARS-CoV-2 infection dynamics in lungs of African green monkeys}

\author{
Emily Speranza',4, Brandi N. Williamson ${ }^{1}$, Friederike Feldmann ${ }^{2}$, Gail L. Sturdevant ${ }^{1}$, Lizzette Pérez- Pérez', \\ Kimberly Meade-White', Brian J. Smith ${ }^{2}$, Jamie Lovaglio ${ }^{2}$, Craig Martens ${ }^{3}$, Vincent J. Munster ${ }^{1}$, Atsushi \\ Okumura $^{1}$, Carl Shaia ${ }^{2}$, Heinz Feldmann' ${ }^{1}$, Sonja M. Best ${ }^{1}$, Emmie de Wit $^{*}$ \\ ${ }^{1}$ Laboratory of Virology, Division of Intramural Research, National Institute of Allergy and Infectious Diseases, National Institutes of Health, Hamilton, MT 59840, United \\ States of America. ${ }^{2}$ Rocky Mountain Veterinary Branch, Division of Intramural Research, National Institute of Allergy and Infectious Diseases, National Institutes of Health, \\ Hamilton, MT 59840, United States of America. ${ }^{3}$ Research Technologies Branch, Division of Intramural Research, National Institute of Allergy and Infectious Diseases, \\ National Institutes of Health, Hamilton, MT 59840, United States of America. ${ }^{4}$ Laboratory of Immune System Biology, Lymphocyte Biology Section, Division of Intramural \\ Research, National Institute of Allergy and Infectious Diseases, National Institutes of Health, Bethesda, MD, United States of America. \\ *Corresponding author. Email: emmie.dewit@nih.gov
}

Detailed knowledge about the dynamics of SARS-CoV-2 infection is important for uncovering the viral and host factors that contribute to COVID-19 pathogenesis. Old-World nonhuman primates recapitulate mild to moderate cases of COVID-19, thereby serving as important pathogenesis models. We compared African green monkeys inoculated with infectious SARS-CoV-2 or irradiated, inactivated virus to study the dynamics of virus replication throughout the respiratory tract. Interestingly, genomic RNA from the animals inoculated with the irradiated virus was found to be highly stable, whereas sub-genomic RNA, an indicator of viral replication, was found to degrade quickly. We combined this information with single-cell RNA sequencing of cells isolated from the lung and lung-draining mediastinal lymph nodes and developed new analysis methods for unbiased targeting of important cells in the host response to SARS-CoV-2 infection. Through detection of reads to the viral genome, we were able to determine that replication of the virus in the lungs appeared to occur mainly in pneumocytes, while macrophages drove the inflammatory response. Interestingly, monocyte-derived macrophages recruited to the lungs, rather than tissue resident alveolar macrophages, were most likely to be responsible for phagocytosis of infected cells and cellular debris early in infection, with their roles switching during clearance of infection. Together, our dataset provides a detailed view of the dynamics of virus replication and host responses over the course of mild COVID-19 and serves as a valuable resource to identify therapeutic targets.

\section{INTRODUCTION}

A wealth of clinical and laboratory studies have been reported concerning severe acute respiratory syndrome coronavirus 2 (SARS-CoV-2), the causative agent of coronavirus disease 2019 (COVID-19) (1,2). A key issue among the many unanswered questions that remain involves the dynamics of SARS-CoV-2 infection, including the identity of the cells that support active virus replication and the immune cells that contribute to the response to infection. Though multiple cell types in the respiratory tract have been reported to express the critical receptor needed for entry, angiotensin-converting enzyme 2 (ACE2), as well as the transmembrane protease, serine 2 (TMPRSS2) needed to initiate replication $(3,4)$, it is not clear which of these cell types is the site of SARS-CoV-2 replication. One study using a new algorithm (Viral Track) to detect viral reads in single cell sequencing samples, suggested that both epithelial cells and macrophages contain viral RNA in human bronchoalveolar lavage fluid (BALF) (5). However, since the presence of genomic RNA (gRNA) alone does not equate to productive virus infection, this study did not address whether this detection of RNA was the result of virus replication in these cells.

Beyond viral replication dynamics, a thorough study of the host response to infection at the major site of virus replication, the lungs, is needed to better understand potential causes of organ damage and targets for therapeutic intervention. The use of single cell technologies such as multi-parameter flow cytometry and single cell sequencing allow for analysis of individual cell states. Sequencing of single cells in BALF (6) and upper respiratory tract swabs (7) collected from patients with COVID-19 has detected markers of severe disease in hospitalized individuals. Others have examined the immune response to infection by utilizing single cell sequencing to profile peripheral blood mononuclear cell samples from patients with COVID-19 $(8,9)$. However, both approaches have limited power to address the dynamics of 
infection, the host response in the lungs, the main site of virus replication, and disease pathogenesis. Furthermore, neither strategy provides insight into the immune response in the lung-draining lymph nodes.

The limitations of human studies with respect to time of sampling relative to exposure, differences in exposure dose and route, and capacity for analyzing tissues in-depth can be overcome using animal models, albeit currently at the cost of not fully replicating the severe disease observed in humans. Indeed, multiple animal models of SARS-CoV-2 infection are being developed to test therapeutics and vaccines and to better understand the dynamics of COVID-19 disease progression and the immune response to infection in a time-resolved manner. Non-human primates are often used as models for infection and pathogenesis since they often recapitulate human disease. African green monkeys are a commonly used non-human primate model for studies of respiratory viruses, including SARS-CoV (10). Recently, two studies showed that inoculation of African green monkeys with SARS-CoV-2 results in mild respiratory disease with virus detected in the upper and lower respiratory tract, suggesting that African green monkeys are a suitable nonhuman primate disease model to study SARS-CoV-2 infection and host response dynamics $(11,12)$.

Here, we used traditional virological methods, single cell RNA sequencing, and immunohistopathology to address some of the major questions about SARS-CoV-2 replication and host responses. Our combined approach, using inoculation with infectious as well as inactivated SARS-CoV-2, determined which cell types are productively infected and assessed the host response to virus replication in the lung. Together, the result is an emerging picture of the viral and immune events associated with mild COVID-19 disease, aiding our understanding of the dynamics of SARS-CoV-2 infection with high resolution.

\section{RESULTS}

Subgenomic RNA, but not genomic RNA, detection reveals active virus replication in the respiratory tract of SARS-CoV-2 infected African green monkeys.

To study SARS-CoV-2 infection and its consequences, two groups of four African green monkeys were inoculated with a total dose of $2.6 \times 10^{6} 50 \%$ Tissue Culture Infectious Dose (TCID50) of replication-competent virus, while two control animals were inoculated with virus inactivated by gamma-irradiation. Clinical signs in the control animals were limited to reduced appetite, likely as a response to repeated anesthesia and intubation, on 0 and 1 days post inoculation (dpi) (Table 1). Tachypnea was observed in five of eight animals inoculated with infectious SARS-CoV-2. In these animals, disease was mild to moderate and transient, with animals recovering between 5 and 9 dpi (fig. S1A and Table 1). At 1 and 3 dpi for all animals and 5, 7, and $10 \mathrm{dpi}$ for 4 of the animals we collected nose, throat, and rectal swabs. High amounts of viral genomic RNA (gRNA) were detected in nose and throat swabs after inoculation with SARS-CoV-2 and declined over time (Fig. 1 A-B). Rectal swabs were positive for gRNA at most time points for one animal with a severely reduced appetite (AGM8) (Fig. 1C).

Nasal swabs, although not throat or rectal swabs, from control animals inoculated with gamma-irradiated virus contained high amounts of gRNA at $1 \mathrm{dpi}$ and were still positive at $3 \mathrm{dpi}$. To determine whether detection of subgenomic RNA (sgRNA) would be able to distinguish between RNA originating from the inoculum from that derived from replicating virus, all swabs positive for gRNA were evaluated by quantitative real time reverse transcriptase polymerase chain reaction (qRT-PCR) to detect subgenomic RNA (sgRNA). Although sgRNA derived from infected, lysing cells in the cell culture in which the virus stock was produced was present at high copy numbers in both inocula, sgRNA could not be detected in swabs collected from control animals. sgRNA was detected in nose and throat swabs from animals inoculated with infectious virus (Fig. 1A and B), indicating that sgRNA likely reflects that virus replication occurred and that gRNA is highly stable, especially in the nasal cavity. Infectious virus could be detected by virus titration early after inoculation in nose and throat swabs; no infectious virus could be detected in rectal swabs (Fig. 1C). As a measure of virus replication in the lower respiratory tract, we collected BALF from the two control animals at 1 and $3 \mathrm{dpi}$ and at 1,3 , and 5 dpi from the four SARS-CoV-2 infected animals euthanized at $10 \mathrm{dpi}$. gRNA could be detected on 1 and 3 dpi in one of the two control animals; however, sgRNA could not be detected. High copy numbers of gRNA and sgRNA were detected in BALF from the four infected animals evaluated, in line with detection of infectious virus through 5 dpi (Fig. 1D).

\section{Virus replication is mostly confined to the lowery respir- atory tract in African green monkeys.}

At $3 \mathrm{dpi}$, the two control animals and four of the SARSCoV-2 infected animals were euthanized. The remaining four SARS-CoV-2 animals were euthanized at $10 \mathrm{dpi}$. Upon necropsy, lungs were examined for gross lesions. No abnormalities were detected in the lungs of the two control animals. At $3 \mathrm{dpi}$, all four animals inoculated with active SARS-CoV-2 showed varying degrees of gross lung lesions and enlarged mediastinal lymph nodes (Table 1 and fig. S1B). By 10 dpi, one animal did not show gross abnormalities whereas the other three animals showed gross lung lesions and enlarged mediastinal lymph nodes (Table 1 and Fig.S1B). Tissue samples from these animals were assessed for the presence of gRNA and sgRNA. Viral gRNA loads were highest in samples collected from the lung lobes and were higher at $3 \mathrm{dpi}$ than 10 dpi. Despite high copy numbers of sgRNA in lung tissue 
through $10 \mathrm{dpi}$, virus could only be isolated at $3 \mathrm{dpi}$ (fig. S1C and Table S1), indicating that in tissue, sgRNA is a much more sensitive detection method than virus isolation in tissue culture. Analysis of other respiratory tract tissues showed that although gRNA can be detected in all tested sites early after inoculation, sgRNA can be detected consistently only in the trachea and right bronchus (fig. S1D).

We also analyzed tissues of the gastrointestinal (GI) tract for the presence of viral RNA. Only gRNA could be detected in the GI tract of several animals after inoculation with SARSCoV-2 at 3 dpi and 10 dpi. However, in AGM8, the animal with severely reduced appetite, high copy numbers of both gRNA and sgRNA could be detected in duodenum, jejunum, ileum, cecum and colon (fig. S1E) and virus was isolated from the ileum and cecum (Table S1). Histologically, the intestinal tract from this animal appeared normal. However, immunohistochemistry (IHC) imaging revealed epithelial cells containing SARS-CoV-2 antigen in the ileum of AGM8 (fig. S2AC).

Histological analysis of the lungs of the two control animals showed no abnormalities (Fig. 2 A-C). The lungs of the four animals inoculated with SARS-CoV-2 and euthanized at 3 dpi showed subtle alveolar thickening, indicative of an early inflammatory response (Fig. 2 D-F). Viral antigen could be detected by IHC in type I pneumocytes and alveolar macrophages of all four animals. Alveolar thickening was still visible in the four animals inoculated with SARS-CoV-2 and euthanized at $10 \mathrm{dpi}$. Two of these animals showed histopathological changes consistent with interstitial pneumonia frequently centered on terminal bronchioles and early lesions in terminal airways, resembling obstructive bronchiolitis (Fig. 2 G-I). At this time, viral antigen could only be detected in type I pneumocytes and alveolar macrophages of one of four animals (AGM10). Three of four mediastinal lymph nodes from the 10 dpi samples exhibited a mild to moderate follicular hyperplasia and the lymph nodes of all four animals exhibited rare mononuclear cell immunoreactivity (fig. S2DE).

\section{RNA sequencing of single cells identified pneumocytes as the main site of productive virus replication.}

On the day of necropsy, we collected sections of the lungs of each animal that contained an active lesion, except in animals where gross lung lesions were not observed at necropsy (Table 1). These sections were processed directly following necropsy into single cell suspensions and single cell RNA sequencing was conducted using cDNA generated immediately without freezing or fixation of the cells, thereby allowing collection of whole cell data. This allowed for high-quality single cell data to be collected with a high fraction of reads in cells (> 80\%) and a low fraction of cells enriched in mitochondrial genes $(<5 \%)$. Uniform manifold approximation and projection (UMAP) was used to display the data with each cell annotated with its likely cell identity (Fig. 3A). For the latter analysis, we developed an algorithm to perform unbiased cell classification, which is a correlation-based method that uses transcriptional profiles from annotated lung tissue and determines the most likely identity for an individual cell or a cluster of cells and learns from the local neighbor information for each cell its most likely identity. To validate the results, we built a marker gene set for each cell type of interest, showing that the expected gene expression profile matched the cell type annotation (Fig. 3B). Using these assignments, we compared the percentage of cells in each sample belonging to each annotation and found an increase in the number of pneumocytes ( $\mathrm{p}$-value of 10dpi to irradiated $=$ 0.06 ) and dividing cells ( $\mathrm{p}$-value of 10dpi to irradiated $=0.04$ ) as infection progressed (fig. S3). This is consistent with the histology results showing an influx of inflammatory cells and type II pneumocyte hyperplasia at $10 \mathrm{dpi}$ (Fig. 2F).

Since SARS-CoV-2 is a poly-adenylated virus, with such modification present in both the genome (gRNA) and the transcripts (sgRNA), we could map reads to both the African green monkey and the SARS-CoV-2 genomes and determine which cell types contained viral RNA. The single cell RNA sequencing (scRNA-Seq) data showed a similar pattern to the qRT-PCR data described, with the highest percentage of positive cells identified at $3 \mathrm{dpi}$ and decreasing by $10 \mathrm{dpi}$ (fig. S1C). Further, no viral RNA was detected in the animals inoculated with gamma-irradiated virus (Fig. 3C and D). We then parsed these data down to individual cell types. At 3 dpi, viral RNA could be detected in several cell types, with the macrophage population having the highest percentage of cells positive for viral RNA (Fig. 3E). The viral RNA in these cells could be due to virus replication, phagocytosis of infected cells, abortive infections, or having virus particles partitioned with cells during creation of gel-beads in emulsion in the 10X genomics processing steps. To discriminate between cells supporting active virus replication versus those containing viral RNA due to other processes, we looked at the distribution of reads across the genome. Due to the $3^{\prime}$ bias of sequencing with the 10X platform, we saw an expected enrichment of reads in the $3^{\prime}$ end (fig. S4A), with a bias to the location of the nucleocapsid $(\mathrm{N})$ gene in the genome. Additionally, in the pseudo-bulk data read pileups, we were able to detect small enrichments of reads in specific areas at the most $3^{\prime}$ end of all the transcripts, including open reading frame (ORF) 1ab, as well as pileups in the first 5000 base pairs (bp) of the ORFlab region (fig. S4B). These points of enrichment in the first $5000 \mathrm{bp}$ matched to locations of non-canonical sgRNA formed by a jump of the RNA-dependent RNA polymerase in ORFlab to N in the SARS-CoV-2 transcriptome and were suggestive of actively replicating virus (13). Based on these findings, we examined each cell type for reads showing such evidence of subgenomic transcripts involving a region other 
than the $\mathrm{N}$ gene. We observed an expected ratio of gene counts across the SARS-CoV-2 genome, where genes closer to $\mathrm{N}$ and longer genes had higher counts associated with them across all cell types. Only one annotated cell type, pneumocytes, had an abnormally high proportion of cells that were positive for the $\mathrm{N}$ gene and for ORF1ab when compared to all other cell types (Fig. 3F). This suggests that despite many cell types containing viral RNA, pneumocytes were likely the dominant cell type supporting productive viral replication, as higher than expected counts to ORFlab is suggestive of high amounts of sgRNA and non-conical sgRNA. To examine this hypothesis further, we performed IHC and in-situ hybridization (ISH) on lung tissues at $3 \mathrm{dpi}$. Although a few macrophages were positive for viral antigen by IHC (Fig. 2F), only pneumocytes were positive by in situ hybridization (ISH) for the viral genome, consistent with the notion that this is the only cell type analyzed supporting active virus replication in the lungs of African green monkeys (Fig. 3G).

\section{Infection-related changes occur in the transcriptional states of cells isolated from the lungs of African green monkeys.}

To gain insight into the biological effects of SARS-CoV-2 infection on diverse cells in the lungs, we examined the transcriptional signatures in cells recovered from animals under each of the viral-exposure conditions. To this end, we developed a new algorithm in which each population of cells was examined for a clustering bias in a pair-wise comparison along individual principal components. We then used the principal component information and gene set enrichment analysis to determine gene signatures driving the differences between two experimental groups. Using this method, we found that macrophages showed large clustering biases in all the comparisons, suggesting they had the biggest transcriptional shift over the course of infection (fig. S5). The $10 \mathrm{dpi}$ samples changes also showed changes in plasma cells and pneumocytes relative to $3 \mathrm{dpi}$, likely due to changes in cell numbers as described above (fig. S5).

The macrophage analysis was extended by selecting and re-analyzing cells that had either a macrophage or monocytelike phenotype and further classified to cells with a more tissue-resident phenotype, indicative of alveolar macrophages, or more monocyte-derived phenotype, indicative of interstitial macrophages and monocytes using the expression of the macrophage receptor with collagenous structure (MARCO) gene (Fig. 4A). The MARCO gene was selected as it is highly expressed in alveolar macrophages and is absent in interstitial macrophages or monocytes based on previous data in human lung samples (14). A comparison of the percentage of the $\mathrm{MARCO}+$ to MARCO- cells showed that, at $3 \mathrm{dpi}$, there was a large influx of monocyte-derived cells, as most of the macrophages detected at that time were MARCO-, consistent with pathology findings in human samples (15). This shift began to normalize by $10 \mathrm{dpi}$ as the animals recovered (Fig. 4B).

To identify the major pathways whose genes were responsible for the analytical differences between these two cell populations, we performed a similar sub-cluster analysis on the MARCO+ versus MARCO- cells (table S2). For the MARCO+ cells, there was a transcriptional shift at $10 \mathrm{dpi}$ along principal component 1 (PC1) (Fig. 4C). Using gene set enrichment analysis, we found pathways associated with lysosomes and extracellular matrix modification enriched along this component, which are also enriched during active phagocytosis (fig. S6A). This suggests these macrophages were active in clearing cell debris from the infected lungs, potentially explaining why the macrophages stain for viral antigen at this timepoint (Fig. 2I). Comparatively, along PC2, we see a shift at $3 \mathrm{dpi}$ and to a lesser extent at $10 \mathrm{dpi}$. The genes associated with this component were enriched for proinflammatory pathways, including the gene set of interferonstimulated genes (Fig. 4C, fig. S6B). In distinction to the MARCO+ cells, we saw a shift for MARCO- cells along PC1, mostly associated with pro-inflammatory pathways in samples at 3 dpi (Fig. 4D, fig. S6C). Along PC2 in the MARCOcells, we see similar pathways that were found in the MARCO+ cells along PC1, suggesting an active phagocytosis state, as well as migratory genes (CD63) (fig. S6D and S6E). This was observed both at 3 and 10 dpi (Fig. 4D). These data suggest that the macrophages were in an inflammatory state at $3 \mathrm{dpi}$ that was beginning to resolve by $10 \mathrm{dpi}$ and that MARCO- macrophages, but not MARCO+ macrophages, were primarily involved in cleanup of cells and cellular debris at 3 dpi.

To assess interactions between macrophages and other cell types, we looked at a combination of the cluster identity as compared to the individual cell identity. Using the same cell identity algorithm, and the clusters calculated by Seurat (16) we looked within individual clusters to identify which cells had a strong macrophage gene marker. At 3 dpi, the clusters associated with pneumocytes, fibroblasts, and endothelial cells all had strong gene markers for macrophages, suggesting these cells were being actively phagocytosed by the macrophages (Fig. 4E). This signature was mostly absent by $10 \mathrm{dpi}$, possibly because the MARCO+ macrophages were picking up more dead cells and cellular debris by this time rather than whole cells with replicating virus (Fig. 4F).

\section{Mediastinal lymph nodes are in an inflammatory state at 3 dpi}

To relate these virus replication and inflammatory changes in the lungs to changes in secondary lymphoid tissues, we sampled cells from the mediastinal lymph nodes. We collected whole mediastinal lymph nodes from animals at the time of necropsy and prepared the samples along with the lung tissue. We were not able to detect any viral RNA in the lymph node by single-cell RNA sequencing, despite a few 
mononuclear cells staining for viral antigen by IHC (fig. S2E). This could be due to low abundance of RNA, low sensitivity of the scRNA-Seq assay in its ability to detect lowly abundant transcripts, or an inability to capture high abundance of nonlymphocyte populations from the lymph node when generating cell suspensions (17). Using an annotation strategy like that used for lung cells, we could detect most of the major cell populations of the lymph node, with most cells annotating as T or B lymphocytes (Fig. 5A). Again, as with the lung, the annotated cell types expressed known marker genes associated with their phenotype (Fig. 5B). The largest transcriptional change observed across all the cell types was an increase in interferon responsive genes at $3 \mathrm{dpi}$, suggesting an inflammatory state in the draining lymph nodes. This transcriptional profile was resolved by $10 \mathrm{dpi}$ and was absent in the lymph nodes from animals that received gamma-irradiated virus (Fig. 5C). The genes characterized in the set at 3 dpi include many classical type I interferon responsive genes (Supplemental Table 2) that are up-regulated across many viral infections.

There was an increase in the percentage of dividing cells (cells identified as in G2M or S-phase) among B cells ( $\mathrm{p}$-value of $10 \mathrm{dpi}$ to irradiated $=0.02$ ) and plasmacytoid dendritic cells ( $p$-value of $10 \mathrm{dpi}$ to irradiated $=0.02$ ) as infection progressed (Fig. 5D). This is consistent with histology findings of lymph node hyperplasia later at 10 dpi (fig. S2D). Evaluation of antibody secreting cells revealed an increase in plasma cells (p-value of 10dpi to $3 \mathrm{dpi}=0.03$, Fig. $5 \mathrm{E}$ ). The development of plasmablasts at 3 dpi in animals that received SARSCoV-2 was lacking (Fig. $5 \mathrm{~F}$ ), potentially due to the inflammatory state of the lymph node and early time of collection. When looking at which cell type showed the strongest transcriptional changes, we found that even at $10 \mathrm{dpi}$, macrophages showed the strongest transcriptional shift when compared to samples from animals inoculated with gammairradiated virus (fig. S7A). Within the macrophage population, we saw an up-regulation in a small subset of macrophages with markers for fully mature monocyte-derived macrophages, such as Chitinase 1, at 10 dpi (fig. S7B).

Further analysis of the $\mathrm{T}$ cells in the mediastinal lymph nodes and their relation to the lung $\mathrm{T}$ cell compartment was performed. To identify CD4 vs. CD8 T cells, we used a similar matching algorithm as above, using splenic T cells as background (14). In both the lung and lymph node T cell compartment, we observed an increase in the percentage of CD4+ T cells in the lung $(\mathrm{p}=0.003)$ and lymph node $(\mathrm{p}=0.0026)$ at 10 dpi relative to irradiated control lungs (fig. S8A-B). We also saw a decrease in proportion of CD8+ T cells at 10 dpi relative to irradiated control lungs $(\mathrm{p}=0.0009)$ and lymph nodes $(\mathrm{p}$ $=0.008$, fig. S8A-B). No change in the regulatory $\mathrm{T}$ cell compartment was observed (fig. S8A-B). We were able to identify a small subset of cells enriched for genes associated with $\mathrm{T}$ follicular helper genes that showed an expansion at $10 \mathrm{dpi}$ in the lymph node (fig. S8C). These cells are often associated with anti-inflammatory cytokines (such as IL-10) which again further suggests that the inflammatory state observed in the lymph node and lung at $3 \mathrm{dpi}$ is being cleared by $10 \mathrm{dpi}$.

\section{DISCUSSION}

This study used large scale single cell sequencing in a nonhuman primate model of SARS-CoV-2 infection. The benefit of using animal models to study SARS-CoV-2 lies in the ability to collect time-resolved datasets of the lungs instead of being limited to sampling at terminal timepoints $(18,19)$. Using traditional virological methods as well as scRNA-Seq, we have begun to parse out the infection dynamics which occur as the disease progresses and virus is eventually cleared in the African green monkey model of mild COVID-19. These findings are consistent with other studies done in African green monkeys $(11,12)$, which share a similar disease pathology to that seen with rhesus macaques (20) and cynomolgus macaques (21). In all cases, the animals display mild disease signs leading to clearance of the virus and recovery.

One unique aspect of this study was the inclusion of two animals inoculated with gamma-irradiated SARS-CoV-2, which renders the virus unable to replicate (22). Unlike previous studies in non-human primate models of disease, this enabled us to directly compare the detection of viral genomic RNA from replicating vs. non-replicating virus. We found that gRNA was highly stable even in the absence of replicating virus and was detectable at 1 and 3 dpi in nose swabs and BALF from the animals inoculated with gamma-irradiated virus, whereas the sgRNA appeared to degrade quickly in swabs in the absence of virus replication. Such viral dynamics could be due to gRNA being encapsulated or due to secondary structures which help prevent degradation (23). This has potential implications in patient testing, as positive gRNA results by PCR may not represent replication-competent SARSCoV-2, especially since the highest amount of gRNA detected in the samples from the animals inoculated with irradiated virus were found in the nasal swabs currently used for most patient diagnostics. Our data suggests that PCR-based tests which specifically target SARS-CoV-2 sgRNA may provide a more realistic signature of replicating virus than detection of gRNA, improving models to determine patient infectivity (24, 25). Since animals cleared sgRNA faster than gRNA the duration of time PCR-positive patients needs to remain in isolation could potentially be reduced.

Using the African green monkey model, we have been able to explore the dynamics of SARS-CoV-2 infection at the time of peak disease in the lungs when most virus replication is occurring. Due to the nature of the 10X genomics platform and the poly-adenylation of the SARS-CoV-2 genome and sgRNA, we were able to determine which cell types were positive for viral RNA in a method similar to previously 
published reports (5), though we did not include any other alignments beyond SARS-CoV-2. To expand upon detection of viral RNA reads, we looked at the distribution of the reads across the genome to determine if we could find a unique pattern of alignment associated with replicating virus. Further investigation into the distribution of reads across the genome suggests that productive virus replication is mostly occurring in infected pneumocytes, though the macrophage population contained the highest percentage of cells positive for viral RNA. These data provide evidence that macrophages do not support efficient virus replication in vivo. A potential reason that the macrophages could have such high viral RNA and immunoreactivity without supporting full replication is through phagocytosis of virus particles or infected cells or through abortive replication. This is similar to what has been observed with SARS-CoV infection, where macrophages can become infected but do not appear to support virus replication (26). Interestingly, abortive replication could result in the production of aberrant replication products that induce a proinflammatory response as has been shown for influenza A virus in the lungs $(27,28)$.

In the conditions examined here, macrophages appeared to be the major drivers of inflammation in the lungs. This is especially interesting as it has been suggested through the study of healthy human tissue that macrophages interact with ACE2 expressing cells at higher frequencies than other populations (4). Both the resident and monocyte-derived macrophages at 3 dpi were enriched for pro-inflammatory genes, likely caused by having higher titers of virus in the lungs driving the inflammatory state. Interestingly, the MARCO+, or tissue-resident, and MARCO-, or monocyte-derived, macrophage populations showed distinct patterns of gene expression in the 3 and 10 dpi samples. The MARCO+ cells were enriched for interferon-stimulated genes at $3 \mathrm{dpi}$, but were enriched in pathways associated with pro-phagocytic lysosomes only at $10 \mathrm{dpi}$ (29). This is surprising, as MARCO+ macrophages have been found to be important in controlling a variety of lung infections $(30,31)$. Only the MARCO- cells at 3 dpi were enriched in genes associated with migration and lysosomes, suggesting that, at $3 \mathrm{dpi}$, the nonalveolar macrophages were playing a more prominent role in lung cleanup. Similar alterations have been observed in severe lung conditions such as chronic obstructive pulmonary disease (32). Follow-up experiments validating and investigating which macrophage populations are responsible for innate immune host defense and for clearing up the lung environment of cellular debris at different stages post-inoculation may help lead to unravel the causes of lung damage and indicate potential targets for therapeutic intervention.

Interferon stimulated genes represented dominant responses in monocyte and macrophage populations in both the lungs and lymph nodes in the early stages of infection but are reduced by the time infection is cleared. In contrast to the African green monkey model, the role of the interferon response has been proposed as a driver of disease if it is induced with delayed kinetics relative to peak virus replication $(33,34)$. Single-cell approaches in human peripheral blood monomuclear cells and BALF from patients stratified by COVID-19 severity have revealed that type I, II and III interferons are sustained at higher amounts in severe patients, while interferons declined in moderate patients over time from symptom onset $(6,9,35)$. In the African green monkey model, monocyte recruitment and interferon-stimulated gene responses were temporally controlled along with virus replication. These responses were diminished in the lungs during recovery and were not sustained in the lymph nodes beyond the stage of peak virus replication. Therefore, the African green monkey model reflects effective viral control and reveals transcriptional signatures within tissues associated with protective responses.

This study presents early evidence of changes during a mild SARS-CoV-2 infection in the African green monkey model. One obvious limitation of the animal model is that it does not recapitulate the more severe manifestations of COVID-19 disease. This is an apparent limitation of all current non-human primate models of SARS-CoV-2 infection (10-12, 20). Additionally, this study does not directly address the more specific development of an adaptive immune response due to lack of T or B cell receptor sequencing, especially at $10 \mathrm{dpi}$. Further studies with this model should be performed to not only increase the sample size being tested, but also to include single cell sequencing of samples of the upper respiratory tract such as nasal brushings and the addition of $\mathrm{T}$ and $\mathrm{B}$ cell receptor sequencing for an in-depth characterization of the adaptive immune response.

Together, the data reported here provide unique insights into the dynamics of SARS-CoV-2 infection over time in the lungs and associated secondary lymphoid tissue, the identity of the cells hosting replicating virus, and the transcriptional changes in these and other cells during this infectious process. Although the African green monkey model did not result in severe disease upon inoculation with SARS-CoV-2, it did allow for a deeper understanding of virus replication, host response dynamics, and gene signatures associated with a successful resolution of infection. Together, these data can be used to inform development of host-targeted therapeutics for SARS-CoV-2 infection.

\section{MATERIALS AND METHODS \\ Study design}

In the search for a nonhuman primate model that recapitulates severe COVID-19, we decided to inoculate African green monkeys with SARS-CoV-2 since they are often used as models for respiratory virus infections and are known to 
develop acute respiratory distress syndrome when inoculated with Nipah virus $(34,35)$. To evaluate the pathogenesis of SARS-CoV-2 in African green monkeys, eight adult African green monkeys ( 4 males, and 4 females, body weight $3.5-6 \mathrm{~kg}$ ) were inoculated via a combination of intranasal $(0.5 \mathrm{ml}$ per nostril), intratracheal $(4 \mathrm{ml})$, oral $(1 \mathrm{ml})$ and ocular $(0.25 \mathrm{ml}$ per eye) administration of a $4 \times 10^{5} \mathrm{TCID} 50 / \mathrm{ml}\left(3 \times 10^{8}\right.$ genome copies/ml) virus dilution in sterile Dulbecco's Modified Eagle Media (DMEM). Two control animals (1 male and 1 female, body weight $4.5-5.5 \mathrm{~kg}$ ) were included in the study for comparison. These animals were inoculated via the same routes with the same dose and volume of inoculum. However, the inoculum was gamma-irradiated to render the virus noninfectious (21). The animals were observed daily (19); the same person assessed the animals throughout the study. The predetermined endpoint for this experiment was 3 days post inoculation (dpi) for the two control animals that were inoculated with irradiated virus and one group of four animals inoculated with infectious SARS-CoV-2, and $10 \mathrm{dpi}$ for the remaining four animals inoculated with infectious SARSCoV-2. Clinical exams were performed on $0,1,3,5,7$, and 10 dpi on anesthetized animals. On exam days, clinical parameters such as body weight, body temperature, and respiration rate were collected, as well as ventro-dorsal and lateral chest radiographs. Blood and nasal, throat, and rectal swabs were collected during all clinical exams. Additionally, on 1, 3, and $5 \mathrm{dpi}$, animals were intubated and bronchoalveolar lavages were performed using $10-20 \mathrm{ml}$ sterile saline. After euthanasia, necropsies were performed. The percentage of gross lung lesions was scored by a board-certified veterinary pathologist and samples of the following tissues were collected: cervical lymph node, conjunctiva, nasal mucosa, nasal septum, oropharynx, tonsil, trachea, all six lung lobes, mediastinal lymph node, right and left bronchus, heart, liver, spleen, kidney, stomach, duodenum, jejunum, ileum, cecum, colon, and urinary bladder. Histopathological analysis of tissue slides was performed by a board-certified veterinary pathologist blinded to the group assignment of the animals.

All animal experiments were approved by the Institutional Animal Care and Use Committee of Rocky Mountain Laboratories at the National Institutes of Health (NIH) and carried out by certified staff in an Association for Assessment and Accreditation of Laboratory Animal Care (AAALAC) International accredited facility, according to the institution's guidelines for animal use, following the guidelines and basic principles in the NIH Guide for the Care and Use of Laboratory Animals, the Animal Welfare Act, United States Department of Agriculture and the United States Public Health Service Policy on Humane Care and Use of Laboratory Animals. African green monkeys were housed in adjacent individual primate cages allowing social interactions, in a climate-controlled room with a fixed light-dark cycle (12-hour light and 12-hour dark). Animals were monitored at least twice daily throughout the experiment. Commercial monkey chow, treats, and fruit were provided twice daily by trained personnel. Water was available ad libitum. Environmental enrichment consisted of a variety of human interaction, manipulanda, commercial toys, videos, and music. The Institutional Biosafety Committee (IBC) approved work with infectious SARS-CoV-2 strains under biosafety level 3 conditions. Sample inactivation was performed according to IBCapproved standard operating procedures for removal of specimens from high containment $(20,22,36,37)$.

\section{Virus and cells}

SARS-CoV-2 isolate nCoV-WA1-2020 (MN985325.1) (38) (Vero passage 3 ) was kindly provided by the Centers for Disease Control and Prevention and propagated once in Vero E6 cells in DMEM (Sigma) supplemented with $2 \%$ fetal bovine serum (Gibco), $1 \mathrm{mM}$ L-glutamine (Gibco), $50 \mathrm{U} / \mathrm{ml}$ penicillin and $50 \mu \mathrm{g} / \mathrm{ml}$ streptomycin (Gibco) (virus isolation medium). Next generation sequencing using Illumina MiSeq showed that the used virus stock was $100 \%$ identical to the initial deposited GenBank sequence (MN985325.1) with 6 SNPs detected in $1-4 \%$ of sequence reads, and no contaminants were detected. Virus was gamma-irradiated with a dose of 2 MRad using a JLS Model 484 Co-60 Irradiator to produce a noninfectious inoculum (22). Absence of infectious virus after gamma-irradiation was confirmed in Vero E6 cells. Vero E6 cells were maintained in DMEM supplemented with $10 \%$ fetal calf serum, $1 \mathrm{mM}$ L-glutamine, $50 \mathrm{U} / \mathrm{ml}$ penicillin and 50 $\mu \mathrm{g} / \mathrm{ml}$ streptomycin.

\section{Quantitative PCR}

RNA was extracted from swabs and BALF using the QiaAmp Viral RNA kit (Qiagen) according to the manufacturer's instructions. Tissues $(30 \mathrm{mg})$ were homogenized in RLT buffer and RNA was extracted using the RNeasy kit (Qiagen) according to the manufacturer's instructions. Five $\mu \mathrm{l}$ RNA was used in a one-step real-time RT-PCR assay to detect gRNA (forward primer 5 $5^{\prime}$ ACAGGTACGTTAATAGTTAATAGCGT- $3{ }^{\prime}$; reverse primer $5^{\prime}$ - ATATTGCAGCAGTACGCACACA-3'; probe 5'-FAMACACTAGCCATCCTTACTGCGCTTCG-3IABkFQ-3' ${ }^{\prime}$ ) and sgRNA (forward primer $5^{\prime}$ CGATCTCTTGTAGATCTGTTCTC-3'; reverse primer $5^{\prime}$ ATATTGCAGCAGTACGCACACA-3'; probe $5^{\prime}$-FAMACACTAGCCATCCTTACTGCGCTTCG-ZEN-IBHQ-3' ') (39, 40) using the Rotor-Gene probe kit (Qiagen) according to instructions of the manufacturer. In each run, standard dilutions of counted RNA standards were run in parallel to calculate copy numbers in the samples.

\section{Virus titration and isolation}

Virus titrations were performed by end-point titration in Vero E6 cells. Cells were inoculated with 10-fold serial 
dilutions of swab and BALF samples. Virus isolation was performed on tissues by homogenizing the tissue in $1 \mathrm{ml}$ DMEM and inoculating Vero E6 cells in a 24 well plate with $250 \mu \mathrm{l}$ of cleared homogenate and a 1:10 dilution thereof. One hour after inoculation of cells, the inoculum was removed and replaced with $100 \mu \mathrm{l}$ (virus titration) or $500 \mu \mathrm{l}$ (virus isolation) medium. Six days after inoculation, CPE was scored and the TCID50 was calculated.

\section{Histopathology}

Histopathology, immunohistochemistry, and in situ hybridization were performed on African green monkey tissues. After fixation for a minimum of 7 days in $10 \%$ neutral-buffered formalin and embedding in paraffin, tissue sections were stained with hematoxylin and eosin (HE). Immunohistochemistry was performed using a custom-made rabbit antiserum against SARS-CoV-2 $\mathrm{N}$ at a 1:1000 dilution, using a CD68 clone KP1 mouse monoclonal antibody (Agilent Dako, \#M0814) at a 1:100 dilution to identify macrophages, and using Cytokeratin clone AE1/AE3 mouse monoclonal antibody (Agilent Dako, \#M3515) at a 1:100 dilution to identify epithelial cells; antibodies were incubated with tissues for 1 hour. Secondary antibodies Discovery OmniMap anti-Rabbit horseradish peroxidase (HRP) (Roche Tissue Diagnostics; cat\# 7604311 predilute) or Discovery OmniMap anti-mouse HRP (Roche Tissue Diagnostics; cat\# 760-4310 predilute) were then incubated with the tissues for $15 \mathrm{~min}$. In situ hybridization was used for detection of SARS-CoV-2 RNA in selected whole tissue sections of the lungs using the RNAscope VS Universal AP assay (Advanced Cell Diagnostics Inc.) as described previously (4I) and using probe directed against the SARS-CoV-2 spike (S) gene (cat\# 848569). Stained slides were analyzed by a board-certified veterinary pathologist.

\section{Single-Cell RNA sequencing of lung and mediastinal lymph node samples}

Lung sections and mediastinal lymph nodes were taken at the time of necropsy and processed. Cell suspensions were generated by manually dicing tissue, enzymatically digesting in RPMI- 1640 containing $0.1 \mathrm{mg} / \mathrm{ml}$ Liberase TM (Sigma Aldrich, 5401127001) and $0.02 \mathrm{mg} / \mathrm{ml}$ DNase I (Sigma Aldrich, $11284932001)$ at $37^{\circ} \mathrm{C}$, and then passing through a $100 \mu \mathrm{m}$ filter (Becton Dickinson). Suspensions were subjected to ACK lysis and final washes in phosphate buffered saline (PBS) containing 0.1\% MACS bovine serum albumin (Miltenyi 130-091386). 10,000 cells were prepared for 10X Genomics gel bead emulsions. The 10X genomics version 3.0 chemistry was used. cDNA for the individual cells was generated and libraries prepped according to the manufacturer's protocol. After final libraries were generated, samples were inactivated for any potentially remaining virus using $500 \mu \mathrm{l}$ of AVL buffer (Qiagen) with $500 \mu \mathrm{l}$ of ethanol with a sample volume of $140 \mu \mathrm{l}$. After a minimum 10-min incubation, samples were removed from the high-containment laboratory following standard protocols and the libraries were extracted from the AVL using the Qiagen AllPrep DNA spin columns (Cat 80204). Samples were then quantified and sequenced. Samples were sequenced on the NextSeq550 using the 10X suggested cycling.

\section{Processing of single-cell RNA sequencing data}

Data were processed through the cellRanger pipeline to perform de-multiplexing and generate count tables. Alignment was done against the African green monkey Ensembl genome (ChlSab1.1) with the SARS-CoV-2 genome (NC_045512.2) included to be able to parse out reads associated with the viral genome. Samples were then read into $\mathrm{R}$ (V3.6.2) using Seurat (V3.1.5) (16). Since samples were collected across two different days (day 3 and day 10 post inoculation), we wanted to account for potential batch effects in the global dataset. For this reason, we then integrated the samples using the IntegrateData function. Cells were filtered that contained abnormally high mitochondrial genes (greater than 3 standard deviations above the median) and cells that were likely doublets were re-labeled (ratio of unique features to unique mapped identifier (UMI) per cell $<0.15$ ). Also, cells containing less than or greater than 3 standard deviations of UMI compared to the population total were removed to filter for noise. Finally, the PCA and UMAP projections were calculated for the samples and clusters of cells were identified. Lung and the lymph node samples were analyzed separately. Gene set enrichment analysis was performed using fgsea (42) and the MSig DB (43) c2cp gene sets.

\section{Cell type identification using single-cell RNA sequenc- ing data}

To determine the identity of either clusters of cells or individual cells, we developed an unbiased method that uses a transcriptional profile of cells instead a few known marker genes. For the reference data, we used an annotated single cell sequencing dataset from (14). For each of the cell type present in the dataset of lung or spleen tissue, we calculated the differential gene expression using the FindMarkers function in Seurat. To find genes strongly associated with each individual cell type, we filtered the data to contain only those genes with an average $\log \mathrm{FC}$ (log fold change) greater than 1 and where the difference in the percentage of cells in the cell type of interest expressing the gene compared to the percentage of cells in all other cell types expressing the gene was greater than 0.5. We used this gene set in either the lung or spleen of the human samples (14) to develop the marker gene set and calculated the average expression of the marker gene set in each cell type. This generated a matrix of the marker genes to cell types. Then a correlation of the marker genes in the annotated data was compared to the individual cell or cluster in the African green monkey dataset. This generated a score for the unknown cell or cluster to a known annotation. Using this method, we found that most clusters contained predominately just one cell type. This is a similar 
method that was developed for the mouse cell atlas (44). The results were validated by looking at the expression of the marker genes across the different cell annotations. Our ratios of cell populations was similar to other studies that have performed similar tissue processing steps to collect lung cells from suspension without any enrichment for a given cell type (14). When determining the identity on an individual cell level, an additional step was added to help correct falsely identified cells. Using the k-nearest neighbors (knn) graph generated in the FindNeighbors function in Seurat, for each cell, its closest neighbors were determined. Once the nearest neighbors were determined, the identities of these neighbors were pulled out. If $>70 \%$ of the nearest neighbors had one specific identity, the cell identity was reassigned as such. This was run multiple times until a stable number of unidentified cells was found (determined by small changes in unknown cell identities). For those that were not able to be identified, the identity from the original transcriptional profile was used. The cell proportions were found to be fairly consistent between individual animals, suggesting there were not additional strong batch effects.

Finally, to identify clusters that were specifically cells undergoing rapid cell division, we used the CellCycleScore function in Seurat to identify which cell cycle each cell was likely in. We then determined that clusters where greater than $95 \%$ of the cells were in G2M or S phase were dividing clusters and were labeled as such.

\section{SARS-CoV-2 read enrichment}

To analyze the enrichment of reads across the SARS-CoV2 genome, we used Integrative Genome Viewer (45) to find read pile-ups. Cells were labeled as positive for viral RNA if they contained any counts to the viral genome.

\section{Clustering biases in scRNA-Seq data}

To determine if there were clustering biases between two cell types, a new method was developed. Across any cluster of cells, the dataset was subset and re-normalized internally to that cluster. Then the significant principal components (containing up to $99 \%$ of the variance explained) were calculated. Along each principal component, the location of the cells was pulled and grouped based on the two conditions that were being compared. The median location of each of the cell populations along the $\mathrm{PC}$ was calculated and the distance measured. This was carried out for all principal components and all clusters. To identify outliers with the strongest clustering bias, points outside the mean and two standard deviations across all the principal components and cell types were noted.

\section{Statistical Analysis}

Statistical tests comparing cell numbers were carried out in GraphPad Prism Version 8 using a one way ANOVA. All comparisons between the three groups are reporting adjusted p-value for multiple testing. A p-value of 0.05 was considered significant. Statistical tests for gene expression in single cell data was carried in Seurat V3.6. Graphs were generated either in ggplot2 (46) or in GraphPad Prism Version 8.

\section{SUPPLEMENTARY MATERIALS}

stm.sciencemag.org/cgi/content/full/scitranslmed.abe8146/DC1

Figure S1. Clinical scores, gross lung lesions and viral loads in respiratory and gastrointestinal tract of African green monkeys inoculated with SARS-CoV-2.

Figure S2. Histological changes in intestinal tract and lymph nodes of African green monkeys infected with SARS-CoV-2.

Figure S3. Percentage of cell types in the lung determined by single cell RNA sequencing

Figure S4. Coverage of reads from the pseudo-bulk data across the SARS-CoV-2 genome.

Figure S5. Clustering bias across cell populations in the lungs.

Figure S6. Gene set enrichment analysis of macrophages across the principal components.

Figure S7. Comparison of different cell populations in the mediastinal lymph node.

Figure S8. Analysis of T cell populations in lung and mediastinal lymph node.

Table S1. Virus isolation from tissues of African green monkeys inoculated with SARSCoV-2 and euthanized at 3 and 10 days post inoculation.

Data file S1. Raw data.

Data file S2. Gene correlations along principal components of the macrophages and ISG gene set.

\section{REFERENCES AND NOTES}

1. M. Z. Tay, C. M. Poh, L. Rénia, P. A. MacAry, L. F. P. Ng, The trinity of COVID-19: Immunity, inflammation and intervention. Nat. Rev. Immunol. 20, 363-374 (2020). doi:10.1038/s41577-020-0311-8 Medline

2. H. Ge, X. Wang, X. Yuan, G. Xiao, C. Wang, T. Deng, Q. Yuan, X. Xiao, The epidemiology and clinical information about COVID-19. Eur. J. Clin. Microbiol. Infect. Dis. 39, 1011-1019 (2020). doi:10.1007/s10096-020-03874-z Medline

3. W. Sungnak, N. Huang, C. Bécavin, M. Berg, R. Queen, M. Litvinukova, C. TalaveraLópez, H. Maatz, D. Reichart, F. Sampaziotis, K. B. Worlock, M. Yoshida, J. L. Barnes; HCA Lung Biological Network, SARS-CoV-2 entry factors are highly expressed in nasal epithelial cells together with innate immune genes. Nat. Med. 26, 681-687 (2020). doi:10.1038/s41591-020-0868-6 Medline

4. F. Qi, S. Qian, S. Zhang, Z. Zhang, Single cell RNA sequencing of 13 human tissues identify cell types and receptors of human coronaviruses. Biochem. Biophys. Res. Commun. 526, 135-140 (2020). doi:10.1016/j.bbrc.2020.03.044 Medline

5. P. Bost, A. Giladi, Y. Liu, Y. Bendjelal, G. Xu, E. David, R. Blecher-Gonen, M. Cohen, C. Medaglia, H. Li, A. Deczkowska, S. Zhang, B. Schwikowski, Z. Zhang, I. Amit, Host-Viral Infection Maps Reveal Signatures of Severe COVID-19 Patients. Cell 181, 1475-1488.e12 (2020). doi:10.1016/i.cell.2020.05.006 Medline

6. M. Liao, Y. Liu, J. Yuan, Y. Wen, G. Xu, J. Zhao, L. Cheng, J. Li, X. Wang, F. Wang, L. Liu, I. Amit, S. Zhang, Z. Zhang, Single-cell landscape of bronchoalveolar immune cells in patients with COVID-19. Nat. Med. 26, 842-844 (2020). doi:10.1038/s41591-020-0901-9 Medline

7. R. L. Chua, S. Lukassen, S. Trump, B. P. Hennig, D. Wendisch, F. Pott, O. Debnath, L. Thürmann, F. Kurth, M. T. Völker, J. Kazmierski, B. Timmermann, S. Twardziok, S. Schneider, F. Machleidt, H. Müller-Redetzky, M. Maier, A. Krannich, S. Schmidt, F. Balzer, J. Liebig, J. Loske, N. Suttorp, J. Eils, N. Ishaque, U. G. Liebert, C. von Kalle, A. Hocke, M. Witzenrath, C. Goffinet, C. Drosten, S. Laudi, I. Lehmann, C. Conrad, L.-E. Sander, R. Eils, COVID-19 severity correlates with airway epitheliumimmune cell interactions identified by single-cell analysis. Nat. Biotechnol. 38 , 970-979 (2020). doi:10.1038/s41587-020-0602-4 Medline

8. W. Wen, W. Su, H. Tang, W. Le, X. Zhang, Y. Zheng, X. Liu, L. Xie, J. Li, J. Ye, L. Dong, X. Cui, Y. Miao, D. Wang, J. Dong, C. Xiao, W. Chen, H. Wang, Immune cell profiling of COVID-19 patients in the recovery stage by single-cell sequencing. Cell Discov. 6. 31 (2020). doi:10.1038/s41421-020-0168-9 Medline

9. A. J. Wilk, A. Rustagi, N. Q. Zhao, J. Roque, G. J. Martínez-Colón, J. L. McKechnie, G. T. Ivison, T. Ranganath, R. Vergara, T. Hollis, L. J. Simpson, P. Grant, A. 
Subramanian, A. J. Rogers, C. A. Blish, A single-cell atlas of the peripheral immune response in patients with severe COVID-19. Nat. Med. 26, 1070-1076 (2020). doi:10.1038/s41591-020-0944-y Medline

10. J. McAuliffe, L. Vogel, A. Roberts, G. Fahle, S. Fischer, W. J. Shieh, E. Butler, S. Zaki, M. St Claire, B. Murphy, K. Subbarao, Replication of SARS coronavirus administered into the respiratory tract of African Green, rhesus and cynomolgus monkeys. Virology 330, 8-15 (2004). doi:10.1016/i.virol.2004.09.030 Medline

11. A. L. Hartman, S. Nambulli, C. M. McMillen, A. G. White, N. L. Tilston-Lunel, J. R. Albe, E. Cottle, M. D. Dunn, L. J. Frye, T. H. Gilliland, E. L. Olsen, K. J. O'Malley, M. M. Schwarz, J. A. Tomko, R. C. Walker, M. Xia, M. S. Hartman, E. Klein, C. A. Scanga, J. L. Flynn, W. B. Klimstra, A. K. McElroy, D. S. Reed, W. P. Duprex, SARSCoV-2 infection of African green monkeys results in mild respiratory disease discernible by PET/CT imaging and shedding of infectious virus from both respiratory and gastrointestinal tracts. PLOS Pathog. 16, e1008903 (2020). doi:10.1371/journal.ppat.1008903 Medline

12. C. Woolsey, V. Borisevich, A. N. Prasad, K. N. Agans, D. J. Deer, N. S. Dobias, J. C. Heymann, S. L. Foster, C. B. Levine, L. Medina, K. Melody, J. B. Geisbert, K. A. Fenton, T. W. Geisbert, R. W. Cross, Establishment of an African green monkey model for COVID-19 and protection against re-infection. Nat. Immunol. 22, 86-98 (2021). doi:10.1038/s41590-020-00835-8 Medline

13. D. Kim, J.-Y. Lee, J.-S. Yang, J. W. Kim, V. N. Kim, H. Chang, The Architecture of SARS-CoV-2 Transcriptome. Cell 181, 914-921.e10 (2020). doi:10.1016/i.cell.2020.04.011 Medline

14. E. Madissoon, A. Wilbrey-Clark, R. J. Miragaia, K. Saeb-Parsy, K. T. Mahbubani, N. Georgakopoulos, P. Harding, K. Polanski, N. Huang, K. Nowicki-Osuch, R. C. Fitzgerald, K. W. Loudon, J. R. Ferdinand, M. R. Clatworthy, A. Tsingene, S. van Dongen, M. Dabrowska, M. Patel, M. J. T. Stubbington, S. A. Teichmann, O. Stegle, K. B. Meyer, scRNA-seq assessment of the human lung, spleen, and esophagus tissue stability after cold preservation. Genome Biol. 21, 1 (2019). doi:10.1186/s13059-019-1906-x Medline

15. C. Wang, J. Xie, L. Zhao, X. Fei, H. Zhang, Y. Tan, X. Nie, L. Zhou, Z. Liu, Y. Ren, L. Yuan, Y. Zhang, J. Zhang, L. Liang, X. Chen, X. Liu, P. Wang, X. Han, X. Weng, Y. Chen, T. Yu, X. Zhang, J. Cai, R. Chen, Z.-L. Shi, X.-W. Bian, Alveolar macrophage dysfunction and cytokine storm in the pathogenesis of two severe COVID-19 patients. EBioMedicine 57, 102833 (2020). doi:10.1016/j.ebiom.2020.102833 Medline

16. T. Stuart, A. Butler, P. Hoffman, C. Hafemeister, E. Papalexi, W. M. Mauck 3rd, Y. Hao, M. Stoeckius, P. Smibert, R. Satija, Comprehensive integration of single-cell data. Cell 177, 1888-1902.e21 (2019). doi:10.1016/i.cell.2019.05.031 Medline

17. M. Y. Gerner, W. Kastenmuller, I. Ifrim, J. Kabat, R. N. Germain, Histo-cytometry: A method for highly multiplex quantitative tissue imaging analysis applied to dendritic cell subset microanatomy in lymph nodes. Immunity 37, 364-376 (2012). doi:10.1016/j.immuni.2012.07.011 Medline

18. T. Menter, J. D. Haslbauer, R. Nienhold, S. Savic, H. Hopfer, N. Deigendesch, S. Frank, D. Turek, N. Willi, H. Pargger, S. Bassetti, J. D. Leuppi, G. Cathomas, M. Tolnay, K. D. Mertz, A. Tzankov, Postmortem examination of COVID-19 patients reveals diffuse alveolar damage with severe capillary congestion and variegated findings in lungs and other organs suggesting vascular dysfunction. Histopathology 77, 198-209 (2020). doi:10.1111/his.14134 Medline

19. S. Tian, Y. Xiong, H. Liu, L. Niu, J. Guo, M. Liao, S.-Y. Xiao, Pathological study of the 2019 novel coronavirus disease (COVID-19) through postmortem core biopsies. Mod. Pathol. 33, 1007-1014 (2020). doi:10.1038/s41379-020-0536-x Medline

20. V. J. Munster, F. Feldmann, B. N. Williamson, N. van Doremalen, L. Pérez-Pérez, J. Schulz, K. Meade-White, A. Okumura, J. Callison, B. Brumbaugh, V. A. Avanzato, R. Rosenke, P. W. Hanley, G. Saturday, D. Scott, E. R. Fischer, E. de Wit, Respiratory disease in rhesus macaques inoculated with SARS-CoV-2. Nature 585, 268-272 (2020). doi:10.1038/s41586-020-2324-7 Medline

21. B. Rockx, T. Kuiken, S. Herfst, T. Bestebroer, M. M. Lamers, B. B. Oude Munnink, D. de Meulder, G. van Amerongen, J. van den Brand, N. M. A. Okba, D. Schipper, P. van Run, L. Leijten, R. Sikkema, E. Verschoor, B. Verstrepen, W. Bogers, J. Langermans, C. Drosten, M. Fentener van Vlissingen, R. Fouchier, R. de Swart, M. Koopmans, B. L. Haagmans, Comparative pathogenesis of COVID-19, MERS, and SARS in a nonhuman primate model. Science 368, 1012-1015 (2020). doi:10.1126/science.abb7314 Medline

22. F. Feldmann, W. L. Shupert, E. Haddock, B. Twardoski, H. Feldmann, Gamma
Irradiation as an Effective Method for Inactivation of Emerging Viral Pathogens Am. J. Trop. Med. Hyg. 100, 1275-1277 (2019). doi:10.4269/ajtmh.18-0937 Medline

23. H. Wakida, K. Kawata, Y. Yamaji, E. Hattori, T. Tsuchiya, Y. Wada, H. Ozaki, N. Akimitsu, Stability of RNA sequences derived from the coronavirus genome in human cells. Biochem. Biophys. Res. Commun. 527, 993-999 (2020). doi:10.1016/i.bbrc.2020.05.008 Medline

24. J. Bullard, K. Dust, D. Funk, J. E. Strong, D. Alexander, L. Garnett, C. Boodman, A. Bello, A. Hedley, Z. Schiffman, K. Doan, N. Bastien, Y. Li, P. G. Van Caeseele, G. Poliquin, Predicting infectious SARS-CoV-2 from diagnostic samples. Clin. Infect. Dis. ciaa638 (2020). doi:10.1093/cid/ciaa638 Medline

25. C. G. Huang, K.-M. Lee, M.-J. Hsiao, S.-L. Yang, P.-N. Huang, Y.-N. Gong, T.-H. Hsieh, P.-W. Huang, Y.-J. Lin, Y.-C. Liu, K.-C. Tsao, S.-R. Shih, Culture-Based Virus Isolation To Evaluate Potential Infectivity of Clinical Specimens Tested for COVID19. J. Clin. Microbiol. 58, e01068-20 (2020). doi:10.1128/JCM.01068-20 Medline

26. M. S. Yip, N. H. Leung, C. Y. Cheung, P. H. Li, H. H. Lee, M. Daëron, J. S. Peiris, R. Bruzzone, M. Jaume, Antibody-dependent infection of human macrophages by severe acute respiratory syndrome coronavirus. Virol. J. 11, 82 (2014). doi:10.1186/1743-422X-11-82 Medline

27. A. J. W. Te Velthuis, J. C. Long, D. L. V. Bauer, R. L. Y. Fan, H.-L. Yen, J. Sharps, J. Y. Siegers, M. J. Killip, H. French, M. J. Oliva-Martín, R. E. Randall, E. de Wit, D. van Riel, L. L. M. Poon, E. Fodor, Mini viral RNAs act as innate immune agonists during influenza virus infection. Nat. Microbiol. 3, 1234-1242 (2018). doi:10.1038/s41564-018-0240-5 Medline

28. M. Brandes, F. Klauschen, S. Kuchen, R. N. Germain, A systems analysis identifies a feedforward inflammatory circuit leading to lethal influenza infection. Cell 154, 197-212 (2013). doi:10.1016/i.cell.2013.06.013 Medline

29. N. A-Gonzalez, J. A. Quintana, S. García-Silva, M. Mazariegos, A. González de la Aleja, J. A. Nicolás-Ávila, W. Walter, J. M. Adrover, G. Crainiciuc, V. K. Kuchroo, C. V. Rothlin, H. Peinado, A. Castrillo, M. Ricote, A. Hidalgo; N. A-Gonzalez et al, Phagocytosis imprints heterogeneity in tissue-resident macrophages. J. Exp. Med. 214, 1281-1296 (2017). doi:10.1084/jem.20161375 Medline

30. M. Arredouani, Z. Yang, Y. Ning, G. Qin, R. Soininen, K. Tryggvason, L. Kobzik, The scavenger receptor MARCO is required for lung defense against pneumococcal pneumonia and inhaled particles. J. Exp. Med. 200, 267-272 (2004). doi:10.1084/iem.20040731 Medline

31. N. Stichling, M. Suomalainen, J. W. Flatt, M. Schmid, M. Pacesa, S. Hemmi, W. Jungraithmayr, M. D. Maler, M. A. Freudenberg, A. Plückthun, T. May, M. Köster, G. Fejer, U. F. Greber, Lung macrophage scavenger receptor SR-A6 (MARCO) is an adenovirus type-specific virus entry receptor. PLOS Pathog. 14, e1006914 (2018). doi:10.1371/journal.ppat.1006914 Medline

32. J. Jubrail, N. Kurian, F. Niedergang, Macrophage phagocytosis cracking the defect code in COPD. Biomed. J. 40, 305-312 (2017). doi:10.1016/j.bj.2017.09.004 Medline

33. R. Channappanavar, A. R. Fehr, R. Vijay, M. Mack, J. Zhao, D. K. Meyerholz, S. Perlman, Dysregulated Type I Interferon and Inflammatory MonocyteMacrophage Responses Cause Lethal Pneumonia in SARS-CoV-Infected Mice. Cell Host Microbe 19, 181-193 (2016). doi:10.1016/i.chom.2016.01.007 Medline

34. R. Channappanavar, A. R. Fehr, J. Zheng, C. Wohlford-Lenane, J. E. Abrahante, M. Mack, R. Sompallae, P. B. McCray Jr., D. K. Meyerholz, S. Perlman, IFN-I response timing relative to virus replication determines MERS coronavirus infection outcomes. J. Clin. Invest. 129, 3625-3639 (2019). doi:10.1172/JCl126363 Medline 35. C. Lucas, P. Wong, J. Klein, T. B. R. Castro, J. Silva, M. Sundaram, M. K. Ellingson, T. Mao, J. E. Oh, B. Israelow, T. Takahashi, M. Tokuyama, P. Lu, A. Venkataraman, A. Park, S. Mohanty, H. Wang, A. L. Wyllie, C. B. F. Vogels, R. Earnest, S. Lapidus, I. M. Ott, A. J. Moore, M. C. Muenker, J. B. Fournier, M. Campbell, C. D. Odio, A. Casanovas-Massana, R. Herbst, A. C. Shaw, R. Medzhitov, W. L. Schulz, N. D. Grubaugh, C. Dela Cruz, S. Farhadian, A. I. Ko, S. B. Omer, A. Iwasaki; Yale IMPACT Team, Longitudinal analyses reveal immunological misfiring in severe COVID-19. Nature 584, 463-469 (2020). doi:10.1038/s41586-020-2588-y Medline

36. S. C. Johnston, T. Briese, T. M. Bell, W. D. Pratt, J. D. Shamblin, H. L. Esham, G. C. Donnelly, J. C. Johnson, L. E. Hensley, W. I. Lipkin, A. N. Honko, Detailed analysis of the African green monkey model of Nipah virus disease. PLOS ONE 10, e0117817 (2015). doi:10.1371/journal.pone.0117817 Medline

37. J. B. Geisbert, V. Borisevich, A. N. Prasad, K. N. Agans, S. L. Foster, D. J. Deer, R. 
W. Cross, C. E. Mire, T. W. Geisbert, K. A. Fenton, An Intranasal Exposure Model of Lethal Nipah Virus Infection in African Green Monkeys. J. Infect. Dis. 221 (Supplement_4), S414-S418 (2020). doi:10.1093/infdis/iiz391 Medline

38. J. Harcourt, A. Tamin, X. Lu, S. Kamili, S. K. Sakthivel, J. Murray, K. Queen, Y. Tao, C. R. Paden, J. Zhang, Y. Li, A. Uehara, H. Wang, C. Goldsmith, H. A. Bullock, L. Wang, B. Whitaker, B. Lynch, R. Gautam, C. Schindewolf, K. G. Lokugamage, D. Scharton, J. A. Plante, D. Mirchandani, S. G. Widen, K. Narayanan, S. Makino, T. G. Ksiazek, K. S. Plante, S. C. Weaver, S. Lindstrom, S. Tong, V. D. Menachery, N. J. Thornburg, Severe Acute Respiratory Syndrome Coronavirus 2 from Patient with Coronavirus Disease, United States. Emerg. Infect. Dis. 26, 1266-1273 (2020). doi:10.3201/eid2606.200516 Medline

39. V. M. Corman, O. Landt, M. Kaiser, R. Molenkamp, A. Meijer, D. K. W. Chu, T. Bleicker, S. Brünink, J. Schneider, M. L. Schmidt, D. G. J. C. Mulders, B. L. Haagmans, B. van der Veer, S. van den Brink, L. Wijsman, G. Goderski, J.-L. Romette, J. Ellis, M. Zambon, M. Peiris, H. Goossens, C. Reusken, M. P. G. Koopmans, C. Drosten, Detection of 2019 novel coronavirus (2019-nCoV) by realtime RT-PCR. Euro Surveill. 25, $\cdots$ (2020). doi:10.2807/15607917.ES.2020.25.3.2000045 Medline

40. R. Wölfel, V. M. Corman, W. Guggemos, M. Seilmaier, S. Zange, M. A. Müller, D. Niemeyer, T. C. Jones, P. Vollmar, C. Rothe, M. Hoelscher, T. Bleicker, S. Brünink, J. Schneider, R. Ehmann, K. Zwirglmaier, C. Drosten, C. Wendtner, Virological assessment of hospitalized patients with COVID-2019. Nature 581, 465-469 (2020). doi:10.1038/s41586-020-2196-x Medline

41. E. de Wit, A. L. Rasmussen, D. Falzarano, T. Bushmaker, F. Feldmann, D. L. Brining, E. R. Fischer, C. Martellaro, A. Okumura, J. Chang, D. Scott, A. G. Benecke, M. G. Katze, H. Feldmann, V. J. Munster, Middle East respiratory syndrome coronavirus (MERS-CoV) causes transient lower respiratory tract infection in rhesus macaques. Proc. Natl. Acad. Sci. U.S.A. 110, 16598-16603 (2013). doi:10.1073/pnas.1310744110 Medline

42. A. Sergushichev, An algorithm for fast preranked gene set enrichment analysis using cumulative statistic calculation. bioRxiv (2016).

43. A. Subramanian, P. Tamayo, V. K. Mootha, S. Mukherjee, B. L. Ebert, M. A. Gillette, A. Paulovich, S. L. Pomeroy, T. R. Golub, E. S. Lander, J. P. Mesirov, Gene set enrichment analysis: A knowledge-based approach for interpreting genome-wide expression profiles. Proc. Natl. Acad. Sci. U.S.A. 102, 15545-15550 (2005). doi:10.1073/pnas.0506580102 Medline

44. X. Han, R. Wang, Y. Zhou, L. Fei, H. Sun, S. Lai, A. Saadatpour, Z. Zhou, H. Chen, F. Ye, D. Huang, Y. Xu, W. Huang, M. Jiang, X. Jiang, J. Mao, Y. Chen, C. Lu, J. Xie, Q. Fang, Y. Wang, R. Yue, T. Li, H. Huang, S. H. Orkin, G.-C. Yuan, M. Chen, G. Guo, Mapping the Mouse Cell Atlas by Microwell-Seq. Cell 173, 1307 (2018). doi:10.1016/i.cell.2018.05.012 Medline

45. J. T. Robinson, H. Thorvaldsdóttir, W. Winckler, M. Guttman, E. S. Lander, G. Getz, J. P. Mesirov, Integrative genomics viewer. Nat. Biotechnol. 29, 24-26 (2011). doi:10.1038/nbt.1754 Medline

46. H. Wickham, ggplot2: Elegant Graphics for Data Analysis. (Springer-Verlag New York, 2016)

47. R. Edgar, M. Domrachev, A. E. Lash, Gene Expression Omnibus: NCBI gene expression and hybridization array data repository. Nucleic Acids Res. 30, 207210 (2002). doi:10.1093/nar/30.1.207 Medline

Acknowledgments: The authors would like to thank Greg Saturday, Dana Scott, Chad Clancy and all Rocky Mountain Veterinary Branch (RMVB) animal caretakers for help with the animal experiments, Anita Mora for help with figure preparations, and Ronald N. Germain for helpful discussions. Funding: This work is supported by the Intramural Research Program of NIAID, NIH to all authors. Author contributions: Conceptualization, E.S., V.J.M., H.F., S.M.B and E.d.W.; animal experiment, B.N.W., F.F., B.J.S., J.L., A.O., E.d.W.; sample processing and analysis - clinical data, F.F., B.J.S., J.L., A.O., E.d.W.; sample processing and analysis - virological data, E.S., B.N.W. L.P.-P., K.M.-W., E.d.W.; sample processing and analysis - single cell Seq data, E.S., G.L.S., C.M.; ; writing-original draft, E.S. and E.d.W.; writing, review and editing, all authors. Competing interests: The authors have no competing interests to declare. Data availability: All data associated with this study are in the paper or supplementary materials. Animal model data have been deposited in Figshare: https://doi.org/10.6084/m9.figshare.12818726.v1. RNA sequencing data have been deposited in NCBI's Gene Expression (47) and are accessible through GEO Series accession number GSE156755 (https://www.ncbi.nlm.nih.gov/geo/query/acc.cgj?acc=GSE156755). This work is licensed under a Creative Commons Attribution 4.0 International (CC BY 4.0) license, which permits unrestricted use, distribution, and reproduction in any medium, provided the original work is properly cited. To view a copy of this license, visit https://creativecommons.org/licenses/by/4.0/. This license does not apply to figures/photos/artwork or other content included in the article that is credited to a third party; obtain authorization from the rights holder before using such material.

Submitted 16 September 2020

Accepted 4 January 2021

Published First Release 11 January 2021

10.1126/scitranslmed.abe8146 


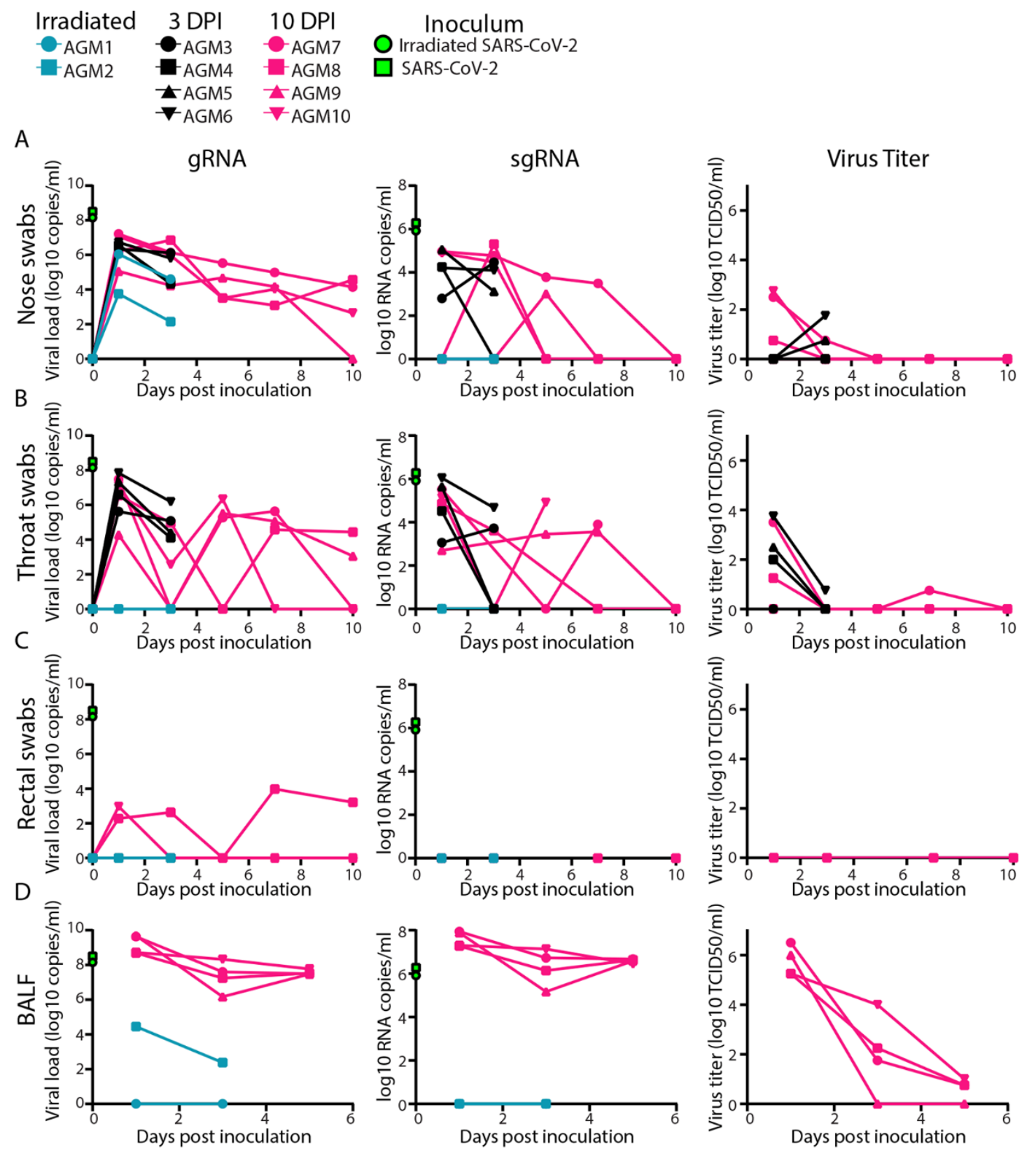

Fig. 1. Viral loads and virus titers in swabs and bronchoalveolar lavage fluid from African green monkeys. Two African green monkeys were inoculated with gamma-irradiated SARS-CoV-2 $(n=2)$. Eight African green monkeys were inoculated with infectious SARS-CoV-2 isolate nCoV-WA1-2020. After inoculation, clinical exams were performed during which nose, throat and rectal swabs were collected; bronchoalveolar lavages (BAL) were performed at 1, 3, and $5 \mathrm{dpi}$ on the four animals remaining in the study through $10 \mathrm{dpi}$ and viral loads and titers were measured. qRT-PCR was performed to detect genomic (left column) and subgenomic RNA (middle column), and in vitro virus titration was performed to detect infectious virus (right column) in these samples. Amount of gRNA and sgRNA in the inocula (gamma-irradiated and infectious) is indicated at timepoint zero. Teal: animals inoculated with gamma-irradiated virus; black: animals inoculated with infectious virus and euthanized at $3 \mathrm{dpi}$; pink: animals inoculated with infectious virus and euthanized at $10 \mathrm{dpi}$. 

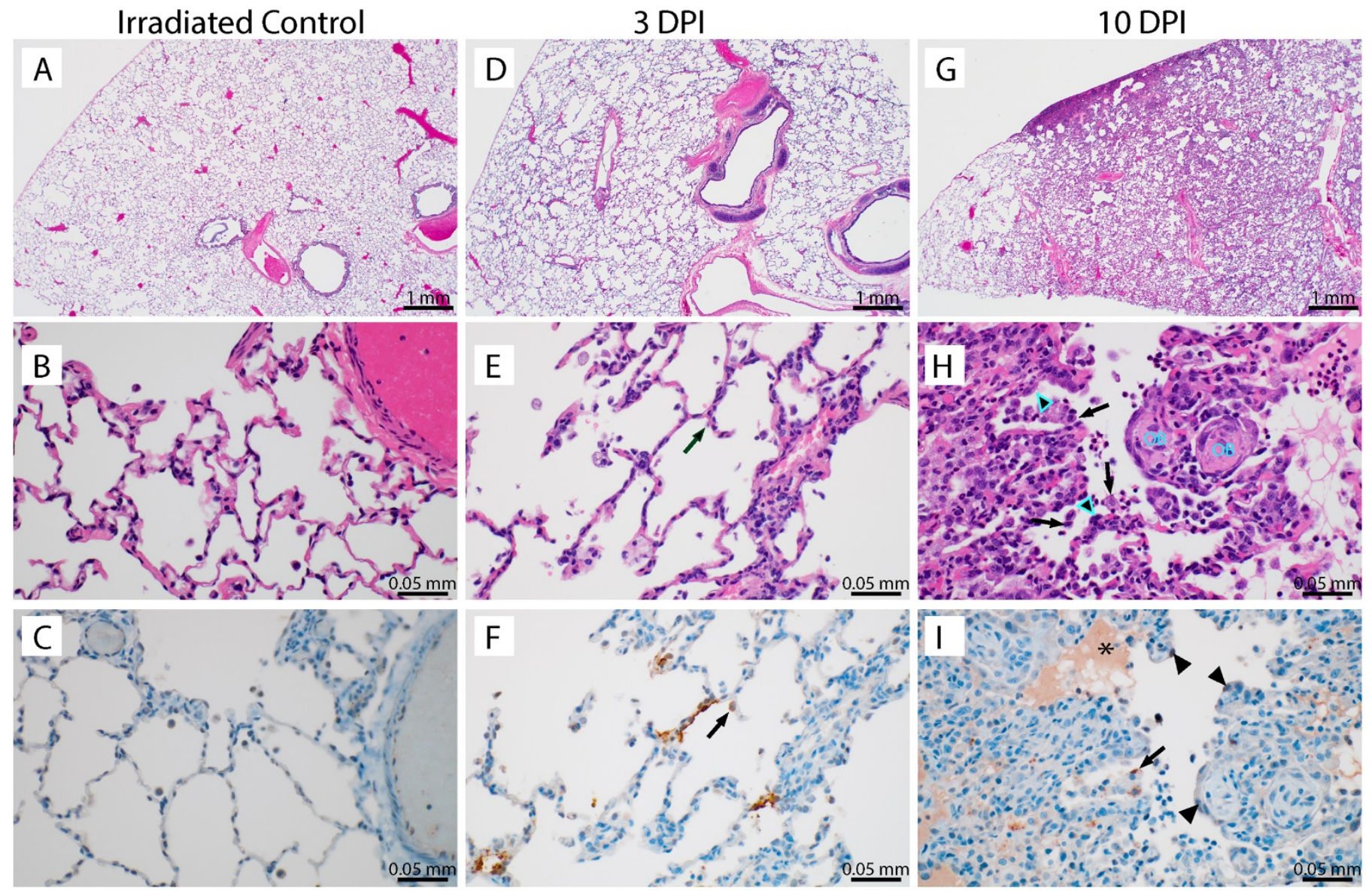

Fig. 2. Histological changes are observed in the lungs of African green monkeys inoculated with SARS-CoV2. (A-C) African green monkeys were inoculated with gamma-irradiated SARS-CoV-2 $(n=2)$ and euthanized at 3 days post inoculation (dpi); eight animals were inoculated with SARS-CoV-2 isolate nCoV-WA1-2020. (D-F) Four of those were euthanized at $3 \mathrm{dpi}$. (G-I) The remaining four animals were euthanized at $10 \mathrm{dpi}$. Histological analysis was performed on lung tissue from all animals. (A) Lungs of animals inoculated with gamma-irradiated SARS-CoV-2 were normal at 3 dpi. (B) this was further confirmed at high magnification. (C) No SARS-CoV-2 antigen could be detected in lungs from animals inoculated with gamma-irradiated SARS-CoV-2. (D) Mildly thickened septa were observed at $3 \mathrm{dpi}$ in animals inoculated with infectious SARS-CoV-2. (E) Alveolar septa are slightly thickened and more cellular at $3 \mathrm{dpi}$. (F) Cytoplasmic and membrane-associated viral antigen in pneumocytes at 3 dpi. (G) Discrete foci of interstitial pneumonia are apparent at the periphery of the lung at 10 dpi. (H) Alveolar edema $\left(^{*}\right)$, type II pneumocyte hyperplasia (arrowhead), increased alveolar macrophages (arrow) and infiltrating lymphocytes and neutrophils are observed at $10 \mathrm{dpi}$, as well as proliferative nodules associated with terminal airways resembling obstructive bronchiolitis (OB). (I) Rare viral antigen could be detected in mononuclear cells, presumably alveolar macrophages, with cytoplasmic debris (arrow) at 10 dpi; background blush is observed in alveolar proteinaceous fluid $\left(^{*}\right)$, but pneumocytes do not exhibit immunoreactivity (arrowhead). Magnification A-C 20x (scale bar = $1 \mathrm{~mm}$ ), D-I 400x (scale bar = $0.05 \mathrm{~mm}$ ). 


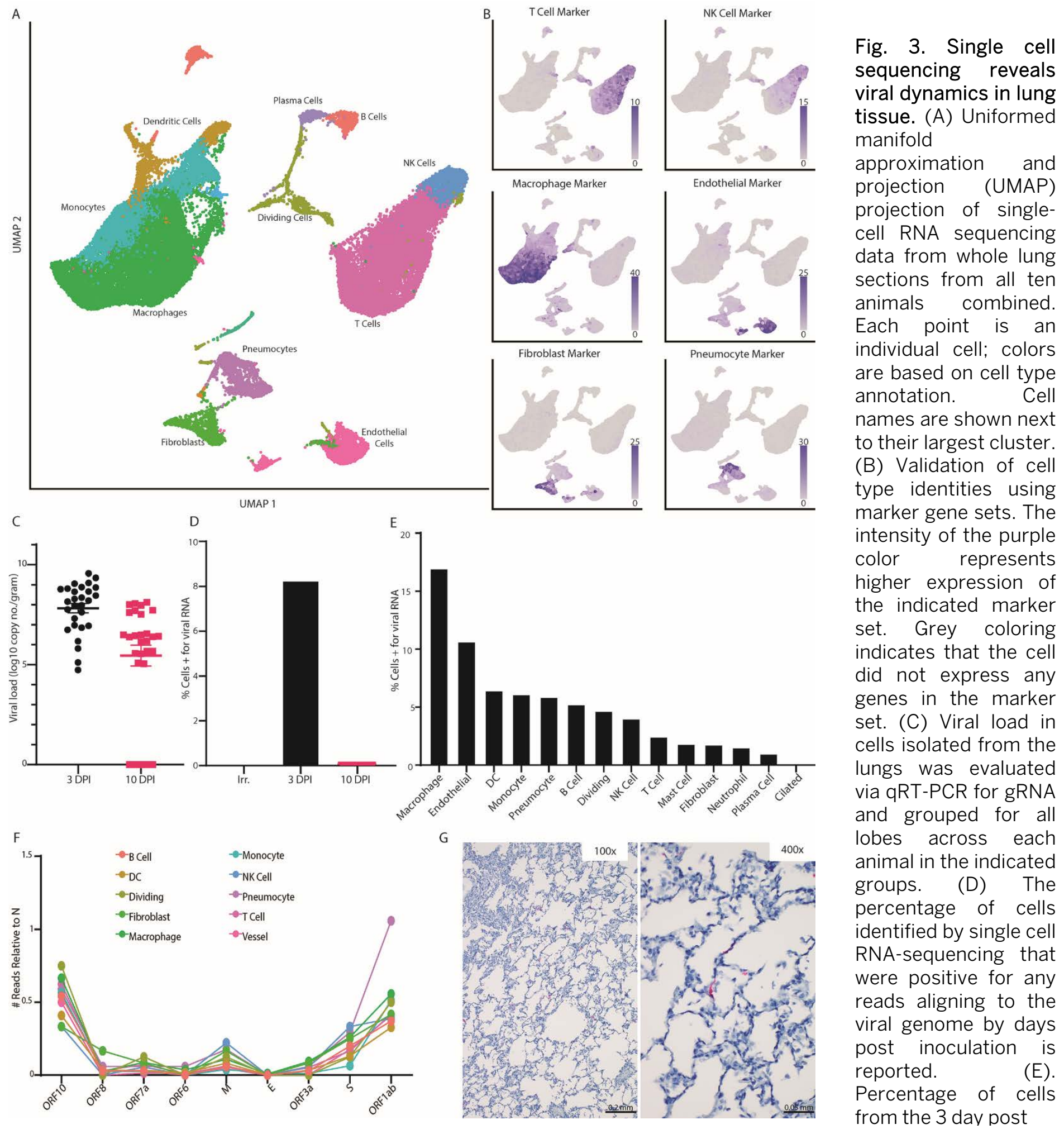

inoculation samples positive for any reads aligning to the viral genome grouped by cell type. (F) The number of cells grouped by cell type with reads aligning to other locations across the viral genome, all normalized to the number of cells expressing nucleocapsid (N) gene. ORF: open reading frame; M: membrane; E: envelope; S: spike. Genes are ordered from the $3^{\prime}$ to $5^{\prime}$ end of the SARS-CoV-2 genome. (G) In situ hybridization for viral spike RNA in lung tissues at 3 dpi. Viral RNA staining is shown in red at 100x magnification (scale bar $=0.2 \mathrm{~mm}$ ) and $400 \times$ magnification (scale bar $=0.05$ $\mathrm{mm})$. 
A
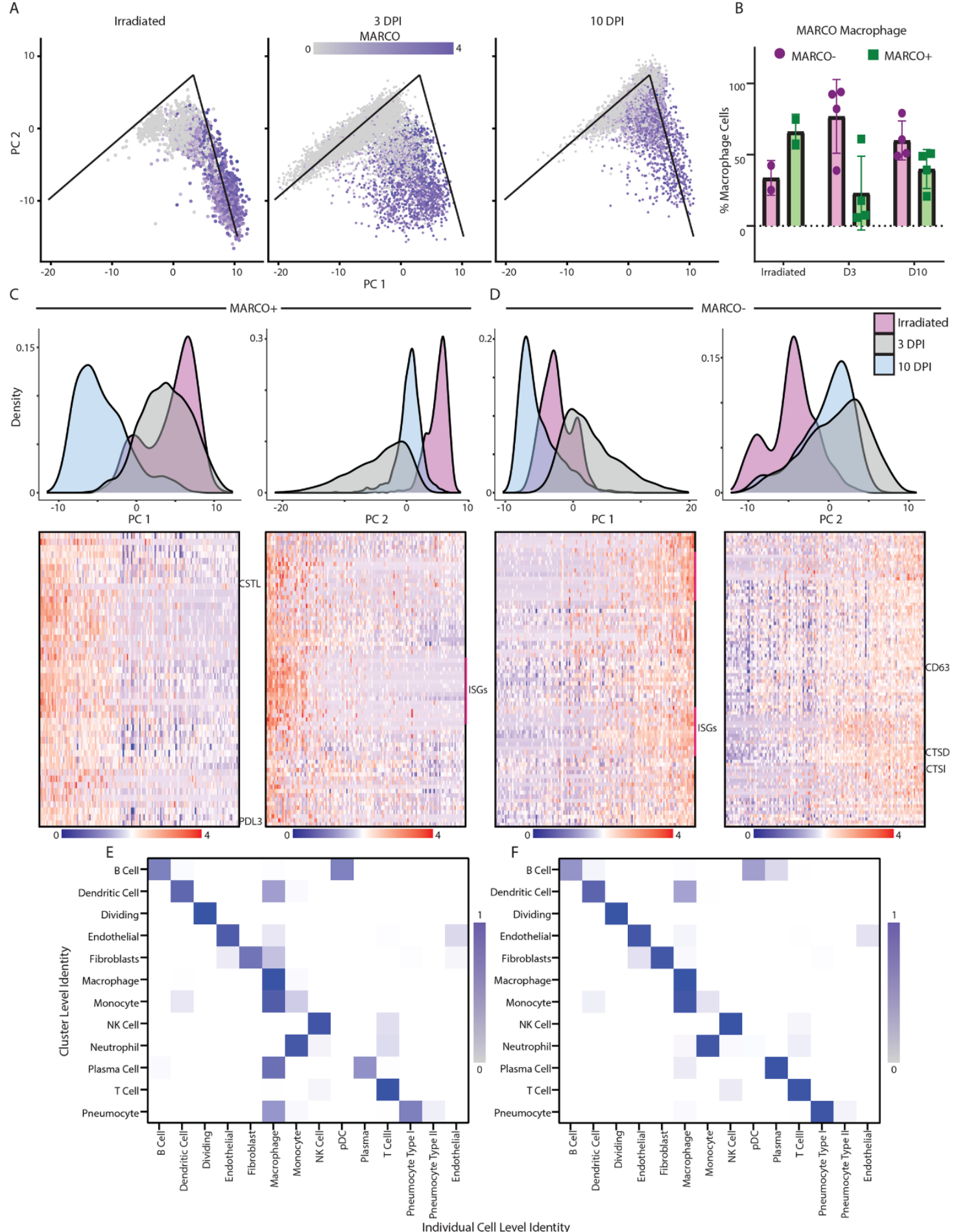

B

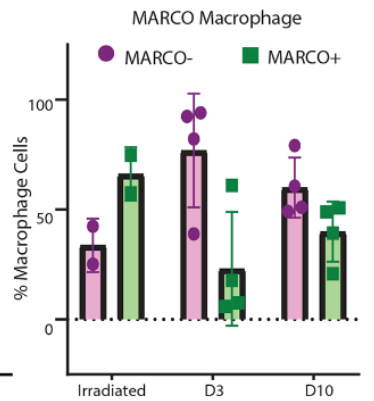

Fig. 4. Macrophage populations in the lungs are dynamic during SARS-CoV-2 infection. (A) Graphs depicting principal component analysis of lung macrophages. The $x$-axis is principal component (PC) 1 and the $y$-axis is $P C$ 2. Experimental groups are plotted independently. Each point is an individual cell and is colored based on the expression of MARCO. The lines on the $P C$ graphs are for reference across the samples and represent matching locations. (B) Quantification of the percentage of macrophages that are MARCO- (purple) or MARCO+ (green) across the three different experimental groups. (C) The MARCO+ macrophages principal component analysis (density plots) were plotted by histograms representing the experimental groups. PC1 is shown on the left and PC2 is shown on the right. The heatmap below showing the individual cells (columns) sorted based on their location along PC 1 or PC 2. Top genes showing high correlation along that principal component are clustered in rows. A few of the gene names are

noted just to the right of the heatmaps. (D) The density plots and histograms are shown as in (C) for MARCO- cells. (EF) The comparison between the individual cell identity (columns) and the cluster identity (rows) based on an unbiased identification algorithm at 3 days post inoculation (dpi) (E) or $10 \mathrm{dpi}(\mathrm{F})$ for SARS-CoV-2-infected animals is shown. The color intensity represent the percent of individual cells in the cluster that match the identified phenotype. 


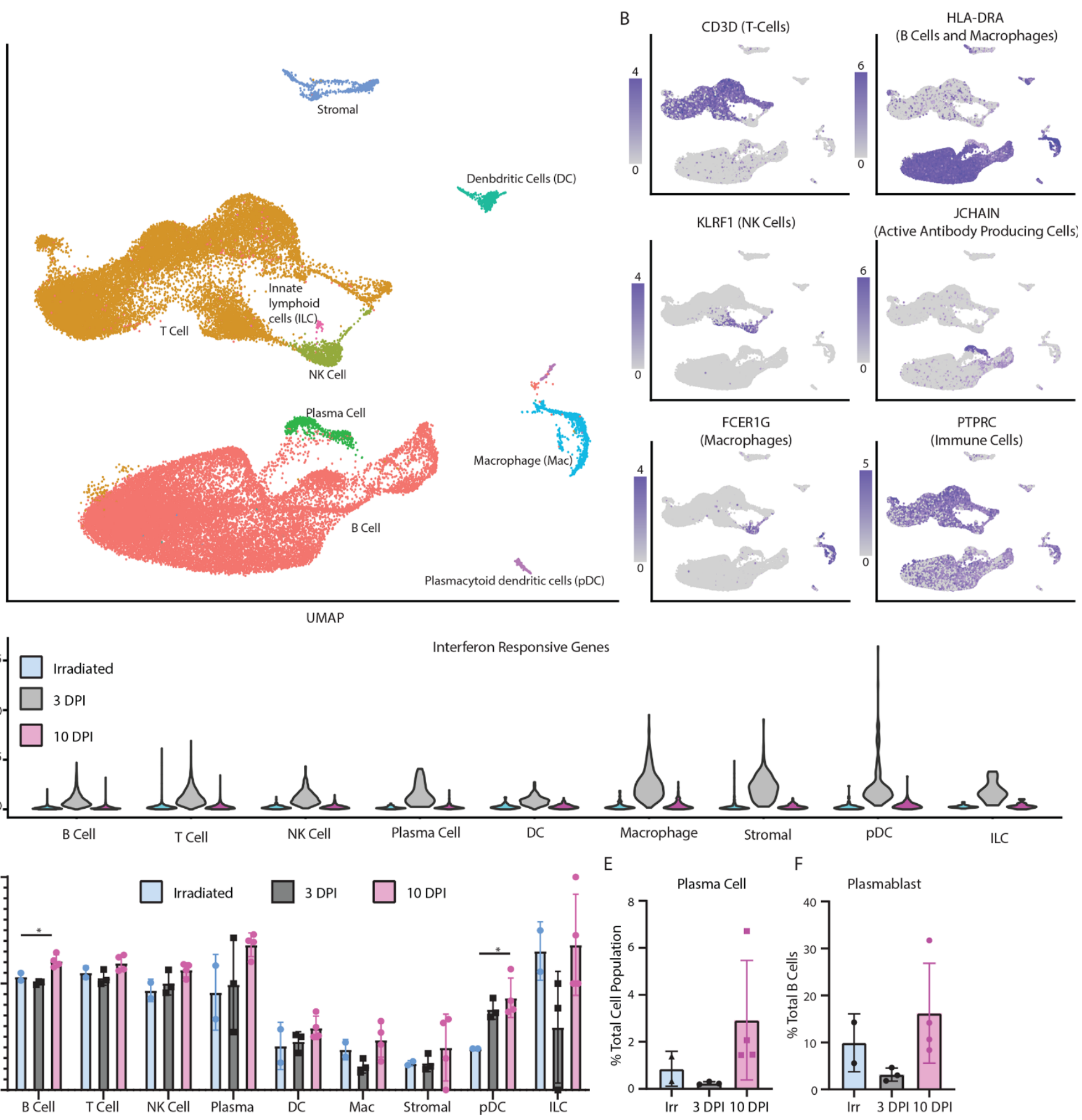

Fig. 5. Single cell sequencing of mediastinal lymph nodes shows resolution of inflammatory response. (A) The Uniform manifold approximation and projection (UMAP) projection of single cell sequencing data from cells isolated from the mediastinal lymph nodes of all ten animals combined is shown. Each point represents an individual cell and cells are colored based on their cell type. The names of the cell types are placed next to their largest cluster. (B) Single gene expression analysis was used to validate cell type identifications. (C) The percent of total gene counts for each cell is shown for a subset of interferon responsive genes ( $y$-axis). The $x$-axis denotes cell types and experimental group. (D) The percentage of each cell population (x-axis) that is actively dividing (stage G2M or S) as determined by a profile of gene expression is shown. Each point is an individual animal and bars represent the mean and standard deviation of the samples. (E) The percentage of plasma cells in each sample compared relative to the total cell number is plotted. (F) The percentage of plasmablast cells relative to the number of $B$ cells is plotted. * indicates adjusted $p$ value $<0.05$ as determined by a one-way ANOVA. 
Table 1. Clinical signs observed in African green monkeys inoculated with irradiated or infectious SARS-CoV-2. Animals were observed daily according to a standardized scoring sheet (19); the same person assessed the animals throughout the study. DPI: days post inoculation.

\begin{tabular}{|c|c|c|c|c|}
\hline Inoculum & Animal & $\begin{array}{l}\text { Clinical signs observed } \\
\text { 1-3 dpi }\end{array}$ & $\begin{array}{l}\text { Clinical signs observed } \\
\text { 4-10 dpi }\end{array}$ & Observations at necropsy \\
\hline \multirow[t]{2}{*}{$\begin{array}{l}\text { Irradiated } \\
\text { SARS-CoV-2 }\end{array}$} & AGM1 & $\begin{array}{l}\text { Reduced appetite. } \\
\text { Euthanized } 3 \text { dpi. }\end{array}$ & N/A & None. \\
\hline & AGM2 & $\begin{array}{l}\text { Reduced appetite. } \\
\text { Euthanized } 3 \text { dpi. }\end{array}$ & $\mathrm{N} / \mathrm{A}$ & None. \\
\hline \multirow[t]{8}{*}{ SARS-CoV-2 } & AGM3 & $\begin{array}{l}\text { Reduced appetite. } \\
\text { Euthanized } 3 \text { dpi. }\end{array}$ & N/A & $\begin{array}{l}\text { Gross lung lesions; cervical and } \\
\text { mediastinal lymph nodes en- } \\
\text { larged. }\end{array}$ \\
\hline & AGM4 & $\begin{array}{l}\text { Tachypnea; reduced } \\
\text { appetite. } \\
\text { Euthanized } 3 \text { dpi. }\end{array}$ & N/A & $\begin{array}{l}\text { Gross lung lesions; mediastinal } \\
\text { lymph nodes mildly enlarged. }\end{array}$ \\
\hline & AGM5 & $\begin{array}{l}\text { Tachypnea; reduced } \\
\text { appetite. } \\
\text { Euthanized } 3 \text { dpi. }\end{array}$ & N/A & $\begin{array}{l}\text { Gross lung lesions; mediastinal } \\
\text { lymph nodes enlarged. }\end{array}$ \\
\hline & AGM6 & $\begin{array}{l}\text { Reduced appetite. } \\
\text { Euthanized } 3 \text { dpi. }\end{array}$ & N/A & $\begin{array}{l}\text { Gross lung lesions; mediastinal } \\
\text { lymph nodes enlarged. }\end{array}$ \\
\hline & AGM7 & Reduced appetite. & $\begin{array}{l}\text { Reduced appetite. } \\
\text { Recovered at } 5 \text { dpi. }\end{array}$ & $\begin{array}{l}\text { Gross lung lesions; mediastinal } \\
\text { lymph nodes enlarged. }\end{array}$ \\
\hline & AGM8 & $\begin{array}{l}\text { Hunched posture; tachyp- } \\
\text { nea; severely reduced } \\
\text { appetite. }\end{array}$ & $\begin{array}{l}\text { Hunched posture; tachyp- } \\
\text { nea; severely reduced appe- } \\
\text { tite. } \\
\text { Recovered at } 9 \text { dpi. }\end{array}$ & $\begin{array}{l}\text { Lungs consolidated; mediastinal } \\
\text { lymph nodes enlarged and hemor- } \\
\text { rhagic. }\end{array}$ \\
\hline & AGM9 & $\begin{array}{l}\text { Tachypnea; reduced } \\
\text { appetite. }\end{array}$ & $\begin{array}{l}\text { Tachypnea; reduced appetite. } \\
\text { Recovered at } 6 \text { dpi. }\end{array}$ & $\begin{array}{l}\text { Gross lung lesions; mediastinal } \\
\text { lymph nodes enlarged. }\end{array}$ \\
\hline & AGM10 & $\begin{array}{l}\text { Hunched posture; tachyp- } \\
\text { nea; coughing; reduced } \\
\text { appetite. }\end{array}$ & $\begin{array}{l}\text { Reduced appetite. } \\
\text { Recovered at } 5 \text { dpi. }\end{array}$ & None. \\
\hline
\end{tabular}

